\title{
Original Article \\ Effect of methotrexate exposure at middle gestation on the inner plate of the ocular cup and lens in the rat fetus
}

\author{
Cheng Zhe $\mathrm{Zu}^{1}$, Masato Kuroki ${ }^{1}$, Ayano Hirako ${ }^{1}$, Takashi Takeuchi ${ }^{1}$, Satoshi Furukawa ${ }^{2}$, and \\ Akihiko Sugiyama ${ }^{*}$ \\ ${ }^{1}$ Department of Veterinary Laboratory Medicine, School of Veterinary Medicine, Faculty of Agriculture, Tottori University, 4-101 \\ Koyama-cho Minami, Tottori, Tottori 680-8553, Japan \\ ${ }^{2}$ Toxicology and Environmental Science Department, Biological Research Laboratories, Nissan Chemical Industries, Ltd., 1470 \\ Shiraoka, Shiraoka-shi, Saitama 349-0294, Japan
}

\begin{abstract}
Pregnant rats were treated intraperitoneally with a single dose of methotrexate (MTX) $90 \mathrm{mg} / \mathrm{kg}$ on gestation day (GD) 13 , and fetal eyeballs were examined time-dependently from GD 13.5 to 15.5. Throughout the experimental period, the inner plate of the ocular cup in the MTX group was significantly thinner than that in the control group. In the inner plate of the ocular cup on GD 15 and 15.5, whereas a developed ganglion cell layer was observed in the control group, the ganglion cell layer in the MTX group was undeveloped and indistinguishable. Disturbance of the arrangement of lens fiber cells, narrowing of the hyaloid cavity of the optic cup, and hypoplasia of optic nerve fibers were observed in the MTX group on GD 15 and 15.5. Increase of pyknosis and decrease of mitosis were induced in the optic cup and the lens epithelium of the MTX group. In the inner plate of the optic cup and the lens epithelium of the MTX group, the cleaved caspase-3- and TUNEL-positive rates increased significantly throughout the experimental period. The phospho-histone H3-positive rate in the inner plate of the optic cup decreased significantly from GD 13.5 to 14.5 , and it recovered on GD 15. On the other hand, the phospho-histone H3-positive rate in the lens epithelium decreased significantly throughout the experimental period. These results suggested that optic tissue on GD 13 in rats was sensitive to MTX. (DOI: 10.1293/tox.2016-0014; J Toxicol Pathol 2016; 29: 173-180)
\end{abstract}

Key words: apoptosis, cell proliferation inhibition, eye, fetus, methotrexate, rat

\section{Introduction}

Methotrexate (MTX) is a dihydrofolate analog that inhibits dihydrofolate reductase, which is important for conversion of dihydrofolate to tetrahydrofolate ${ }^{1}$. Consequently, MTX prevents the pyrimidine and purine synthesis required for DNA and RNA synthesis and inhibits cell proliferation $^{2}$. MTX also induces apoptosis via the upregulation of p53 and p21 proteins $\mathrm{s}^{3,4}$, repression of the induction of c-Jun N-terminal kinase (JNK) activity 4 , expression of the CD95 receptor/ligand system 5 , or elevation of the reactive oxygen species level ${ }^{5,6}$. MTX has been used for the treatment of neoplastic disease, rheumatic disorders, Crohn disease, systemic lupus, psoriasis, and intrinsic asthma ${ }^{7,8}$. MTX is also used for the medical management of ectopic pregnancy and

Received: 14 February 2016, Accepted: 6 April 2016

Published online in J-STAGE: 24 April 2016

*Corresponding author: A Sugiyama

(e-mail: sugiyama@muses.tottori-u.ac.jp)

(C2016 The Japanese Society of Toxicologic Pathology

This is an open-access article distributed under the terms of the Creative Commons Attribution Non-Commercial No Derivatives (by-ncnd) License $<$ http://creativecommons.org/licenses/by-nc-nd/4.0/> . as an abortifacient in pregnancy ${ }^{8,9}$.

Fetal MTX syndrome results from failed medical abortion with MTX, or when mothers who are taking MTX for medical reasons become pregnant inadvertently ${ }^{8}$. The most common anomalies of fetal MTX syndrome include growth deficiency, craniofacial deformities, central nervous system anomalies, and skeletal defects 8 . Small eyes reportedly resulted from failed medical abortion by the use of MTX in combination with misoprostol in a 5-month-old human infant $^{10}$. On the other hand, intravenous administration of MTX $19.2 \mathrm{mg}$ on any of gestation day (GD) 10, GD 11, or GD 12 induced microphthalmia in the rabbit ${ }^{11}$. However, there are few reports to date describing the detailed histopathological findings of the ocular disorders induced by prenatal MTX administration, and effects of prenatal MTX treatment on fetal eye development have not been completely elucidated. Therefore, in the present study, we examined histopathologically the time-dependent changes of the fetal eyeball following MTX treatments on GD 13, to clarify the effect of MTX on eye development. 


\section{Material and Methods}

\section{Animals}

All experiments were performed using female WistarImamichi rats that were 9-10 weeks of age and obtained from the Institute of Animal Reproduction (Kasumigaura, Japan). The animals were reared in a room with the temperature controlled at $22 \pm 2{ }^{\circ} \mathrm{C}$, the humidity controlled at $50 \pm$ $5 \%$, ventilation 11 times per hour, and a 12:12-h light/dark cycle (light cycle, 7:00-19:00), and they were given standard chow (CE-2, CLEA Japan, Inc., Tokyo, Japan). The present experiments were performed following the provisions approved by the Animal Research Committee of Tottori University.

\section{Experimental design}

Pregnant rats were treated with MTX on GD 13, and fetal eyeballs were examined time-dependently. A total of 30 animals were divided into two groups as follows: (1) salinetreated control rats $(\mathrm{n}=15)$ and $(2)$ MTX-treated rats $(\mathrm{n}=$ 15). MTX (Pfizer Japan Inc., Tokyo, Japan) was dissolved in saline. Day 0 of gestation (GD 0) was designated as the day when the presence of a vaginal plug was identified. The rats received intraperitoneal injections (i.p.) of MTX $(90 \mathrm{mg} / \mathrm{kg}$ body weight) or saline (the control) on GD 13. The specific timing of MTX administration we used was selected because the injection of DNA-damaging chemicals such as busulfan in this period induced significant apoptotic changes in the inner plate of the optic cup of rat fetuses ${ }^{12}$. Additionally, GD 13 in rats is also the time at which optic cup formation is completed $^{13}$. The dose of MTX in the present study was designated as $90 \mathrm{mg} / \mathrm{kg}$ based on the results of our preliminary study, in which MTX $10 \mathrm{mg} / \mathrm{kg}$ treatment on GD 13 induced few histopathological changes in the inner plate of the optic cup. Although MTX $30 \mathrm{mg} / \mathrm{kg}$ treatment on GD 13 induced pyknotic changes in the inner plate of the optic cup, the pyknotic rate was uneven, and individual differences in the pyknotic rate were observed in this administered group. MTX $90 \mathrm{mg} / \mathrm{kg}$ treatment caused pyknotic changes stably in the inner plate of the optic cup, and no individual differences in the pyknotic rate were observed in this administered group. Fetus samples were collected after euthanasia by overdose administration of pentobarbiturate (100 mg/kg, i.p.) on GD $13.5,14,14.5,15$, and 15.5 . The percentage of the number of live fetuses to the total number of live and dead fetuses in an individual litter was calculated as the fetal survival rate. The thickness of the inner plate of the optic cup was measured in the region $50 \mu \mathrm{m}$ away from the optic disk.

\section{Histopathological examination}

For histopathological examination, all fetuses were fixed in $10 \%$ neutral buffered formalin and then embedded in paraffin. The fetal eyes were sectioned, stained with hematoxylin and eosin, and examined with light microscopy.

\section{TUNEL method}

DNA-fragmented cells in the inner plate of the optic cup and the lens epithelium were detected by terminal deoxynucleotidyl-transferase (TdT)-mediated deoxyuridine triphosphate-digoxigenin (dUTP) nick-end labeling (TUNEL), which was performed using an in situ apoptosis detection kit (Trevigen, Inc., Gaithersburg, MD, USA). The TUNEL-positive rate in the inner plate of the optic cup and the lens epithelium was calculated as the percentage of TUNEL-positive cells out of the total number of component cells counted.

\section{Immunohistochemical examinations}

Immunohistochemical staining was performed by a labeled-polymer method using Histofine Simple Stain MAXPO (R) (Nichirei, Tokyo, Japan). To retrieve the antigen, tissue sections for the detection of cleaved caspase- 3 antigen were immersed in citrate buffer, $\mathrm{pH} 6.0$ (Dako, Glostrup, Denmark), and autoclaved for $15 \mathrm{~min}$ at $121^{\circ} \mathrm{C}$; and tissue sections for the detection of phospho-histone $\mathrm{H} 3$ antigen were immersed in citrate buffer, pH 6.0 (Dako, Glostrup, Denmark), and microwaved for $15 \mathrm{~min}$. Because histone H3, a protein involved in chromatin structure, is phosphorylated at serine 10 during chromatin condensation in mitosis $^{14}$, phosphor-histone H3 is recognized as a mitosisspecific marker ${ }^{15,16}$. Endogenous peroxidase activity was quenched by immersing the sections in $3 \%$ hydrogen peroxide in methanol for $15 \mathrm{~min}$. The sections were incubated with the cleaved caspase-3 rabbit polyclonal antibody (1:200 dilution; Cell Signaling Technology, Inc., Danvers, MA, USA) for $30 \mathrm{~min}$ at room temperature, and the sections were incubated with the phospho-histone $\mathrm{H} 3$ rabbit monoclonal antibody (1:1500 dilution; Abcam, Tokyo, Japan) for $30 \mathrm{~min}$ at room temperature and then treated with Histofine Simple Stain MAX-PO (R) (Nichirei, Tokyo, Japan) for $30 \mathrm{~min}$ at room temperature. They were exposed to a 3,3'-diaminobenzidine solution containing hydrogen peroxide (Nichirei, Tokyo, Japan) to facilitate a peroxidase color reaction and then counterstained with Mayer's hematoxylin. The cleaved caspase-3-positive rate and the phospho-histone H3-positive rate were calculated as the percentage of cleaved caspase3-positive cells and phospho-histone H3-positive cells out of the total number of component cells counted.

\section{Statistical analysis}

Means \pm SE of the individual litter value were calculated. Comparisons between the two groups were made by Student's $t$-test or Welch's $t$-test if the data were normally distributed or by Mann-Whitney $U$ test if the data were not normally distributed, with the "Excel Toukei 2008" statistical software being used for the comparisons (SSRI Co., Ltd., Tokyo, Japan). The data were analyzed with an $F$-test. When variances were homogenous, the Student's $t$-test was performed. Welch's $t$-test was employed when variances were not homogeneous $(P<0.05) . P<0.05$ or $P<0.01$ was considered to be statistically significant. 


\section{Results}

On GD 13.5, 14, and 14.5, there were no significant differences in the fetal survival rate between the control group and the MTX group (Fig. 1). On GD 15 and 15.5, the fetal survival rate in the MTX group significantly declined compared with those of the control group (Fig. 1). Throughout the experimental period, the fetuses in the MTX group were small and their body weights were significantly reduced compared with the control group (Fig. 2).

Eyeballs in the MTX group were small compared with those in the control group on GD 15 and 15.5 (Fig. 3). Throughout the experimental period, the inner plate of the optic cup in the MTX group was significantly thinner than that in the control group (Figs. 3, 4, and 7). In the inner plate of the optic cup on GD 15 and 15.5, whereas the ganglion cell layer in the control group developed, the ganglion cell layer in the MTX group was undeveloped and indistinguishable (Fig. 4). Disturbance of the arrangement of the lens fiber cells, narrowing of the hyaloid cavity of the optic cup, and incomplete development of the optic nerve were observed in the MTX group on GD 15 and 15.5 (Figs. 3, 5, and 6). Increase of pyknosis and decrease of mitosis were observed in the inner plate of the optic cup and the lens epithelium in the MTX group (Fig. 8). The pyknotic cells in the inner plate of the optic cup and the lens epithelium were positive for cleaved caspase-3 and TUNEL staining (Figs. 9 and 10). In the inner plate of the optic cup and the lens epithelium of the MTX group, the cleaved caspase-3- and TUNEL-positive rates increased significantly throughout the experimental

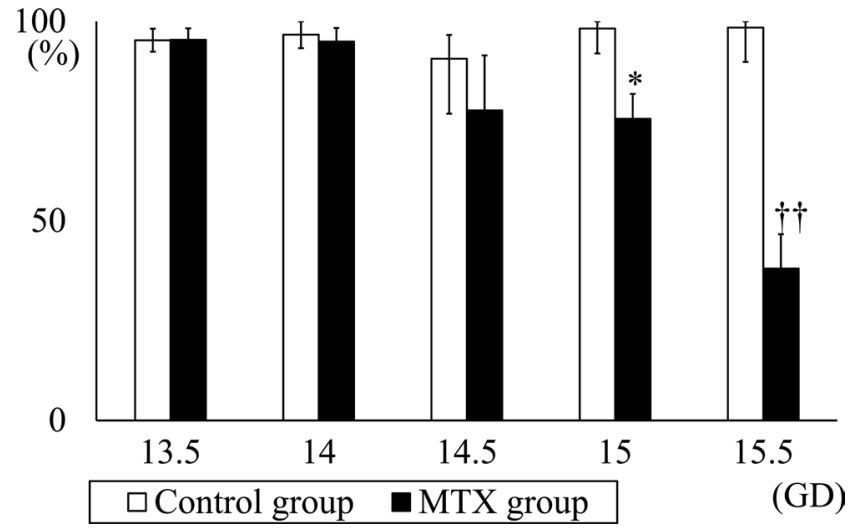

Fig. 1. Time course changes in fetal survival rate. *Significantly different from the control group at $p<0.05$ (Student's $t$-test). ${ }^{\dagger}$ Significantly different from the control group at $p<0.01$ (Welch's $t$-test).
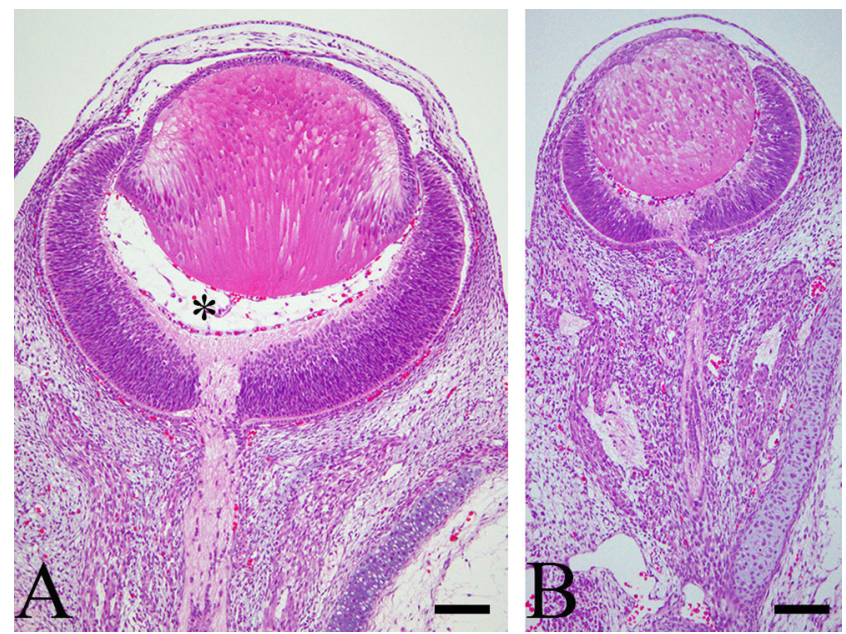

Fig. 3. Histopathological changes in the eyeball induced by MTX on GD 15.5. A. Control group. B. MTX group. *Hyaloid cavity of optic cup. Bar $=100 \mu \mathrm{m}$.

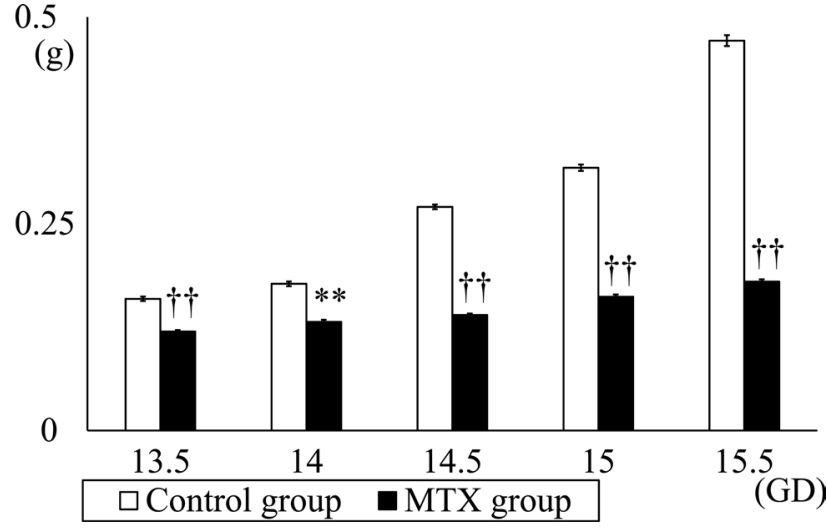

Fig. 2. Time course changes in fetal body weight. **Significantly different from the control group at $p<0.01$ (Student's $t$-test). ${ }^{\dagger}$ Significantly different from the control group at $p<0.01$ (Welch's $t$-test).

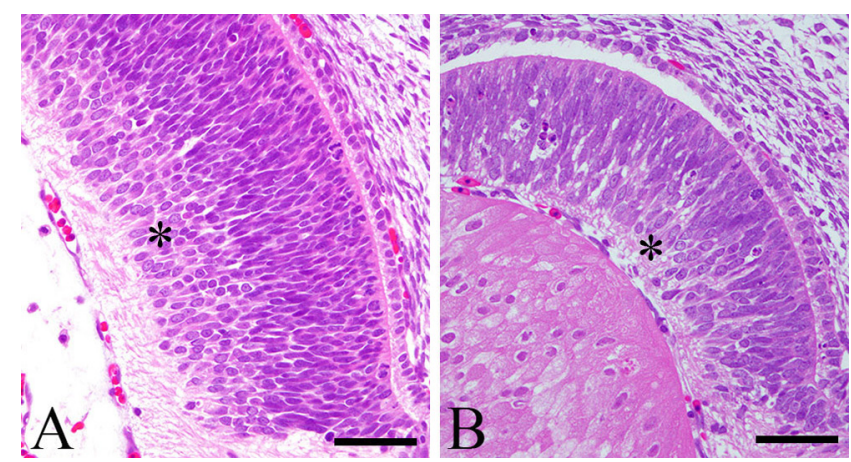

Fig. 4. Histopathological changes in inner plate of optic cup induced by MTX on GD 15.5. A. Control group. B. MTX group. *Ganglion cell layer. $\mathrm{Bar}=50 \mu \mathrm{m}$. 


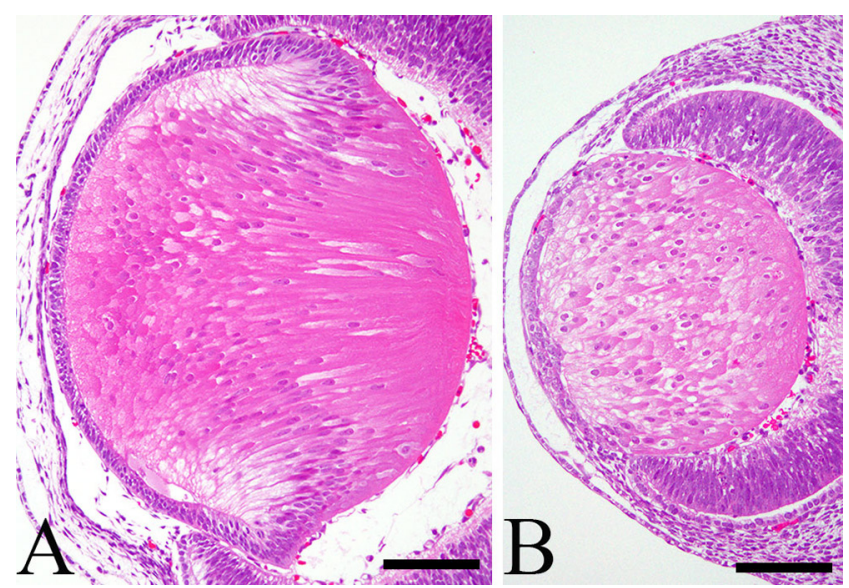

Fig. 5. Histopathological changes in the lens induced by MTX on GD 15.5. A. Control group. B. MTX group. Bar $=100 \mu \mathrm{m}$.

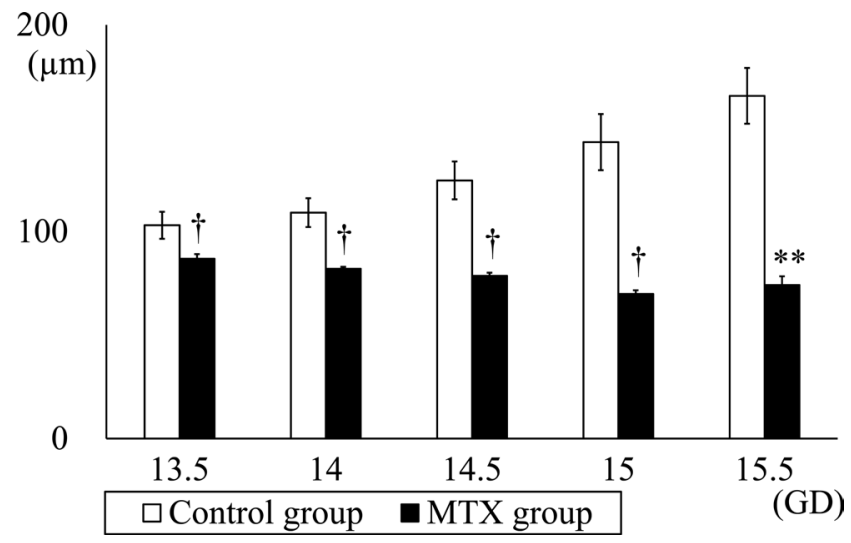

Fig. 7. Time course changes in inner plate thickness of the optic cup in rat fetuses. Values are expressed as means \pm SE. **Significantly different from the control group at $p<0.01$ (Student's $t$ test). ${ }^{\dagger}$ Significantly different from the control group at $p<0.05$ (Welch's $t$-test).

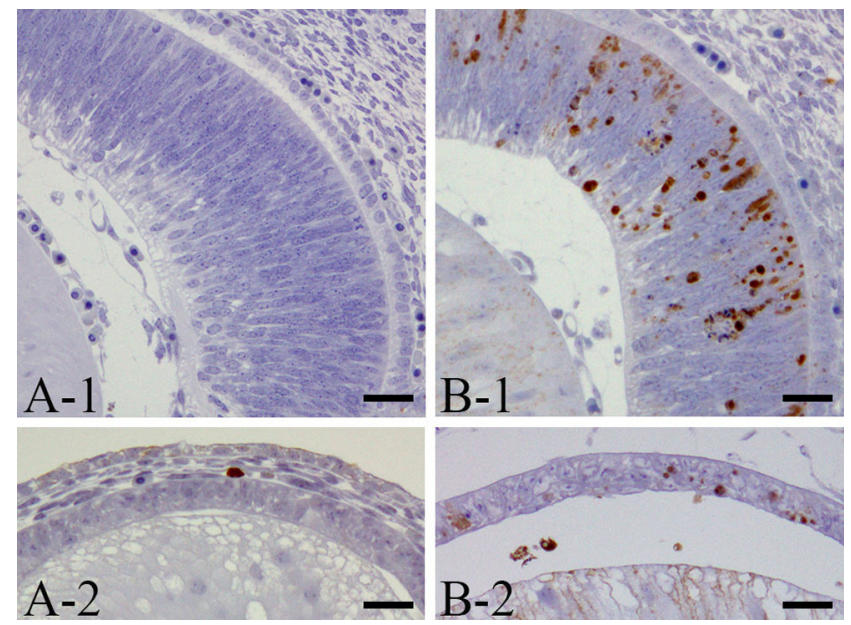

Fig. 9. Cleaved caspase- 3 expression in the inner plate of the optic cup (1) and lens epithelium (2) induced by MTX on GD 14. A. Control group. B. MTX group. Immunohistochemistry for cleaved caspase-3. Bar $=30 \mu \mathrm{m}$.

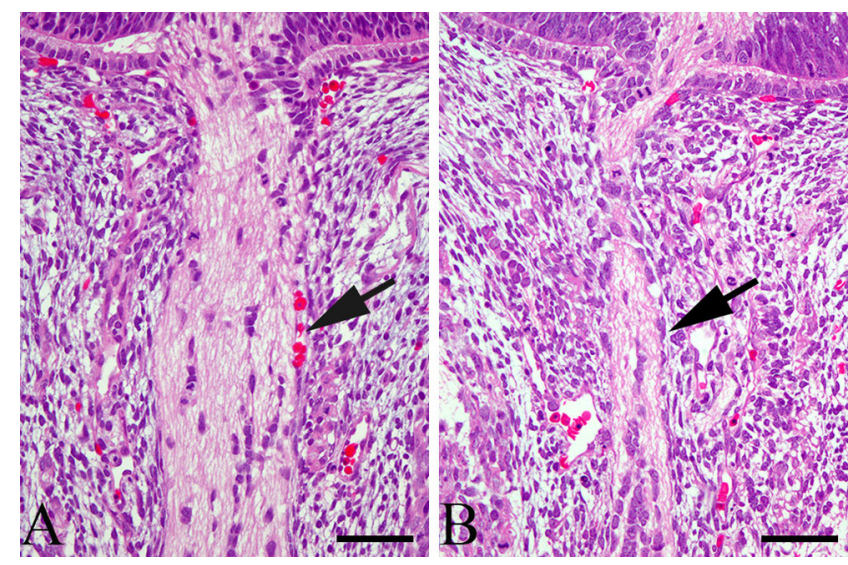

Fig. 6. Histopathological changes in the optic nerve induced by MTX on GD 15.5. A. Control group. B. MTX group. $\mathrm{Bar}=50$ $\mu \mathrm{m}$. Arrows show the optic nerve.
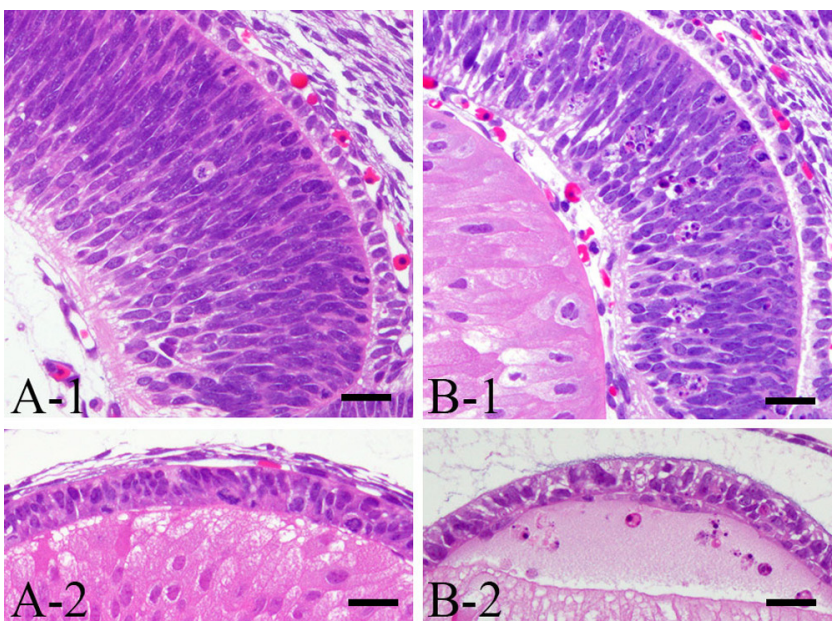

Fig. 8. Pyknotic changes in the inner plate of the optic cup (1) and lens epithelium (2) induced by MTX on GD 14.5. A. Control group. B. MTX group. HE stain. Bar $=30 \mu \mathrm{m}$.

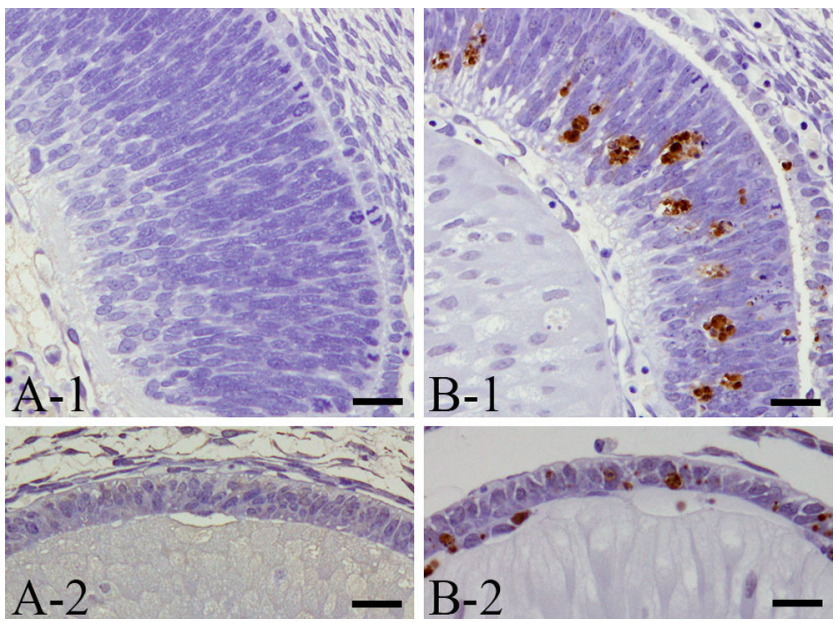

Fig. 10. TUNEL-positive cells in the inner plate of the optic cup (1) and lens epithelium (2) induced by MTX on GD 15. A. Control group. B. MTX group. TUNEL stain. Bar $=30 \mu \mathrm{m}$. 
period (Figs. 9, 10, and 12). Whereas the cleaved caspase3 -positive rate in the inner plate of the optic cup tended to be high from GD 14 to 15 , the TUNEL-positive rate in the inner plate of the optic cup tended to be high from GD 14.5 to 15.5 (Fig. 12). Meanwhile, the cleaved caspase-3-positive rate in the lens epithelium tended to be high from GD 13.5 to 14.5 , and the TUNEL-positive rate in the inner plate of the optic cup tended to be high from GD 15 to 15.5 (Fig. 12). On GD 13.5, whereas there were many phospho-histone H3positive cells in the inner plate of the optic cup and the lens epithelium in the control group, only a few phospho-histone H3-positive cells existed in the same regions in the MTX group (Fig. 11). The phospho-histone H3-positive rate in the inner plate of the optic cup decreased significantly from GD 13.5 to 14.5 , and it recovered on GD 15 (Figs. 11 and 12). On the other hand, the phospho-histone $\mathrm{H} 3$-positive rate in the lens epithelium decreased significantly during the entire experimental period, and no recovery was observed (Figs. 11 and 12).

\section{Discussion}

In the present study, MTX treatment on GD 13 induced marked apoptotic changes and cell proliferation inhibition in the inner plate of the optic cup and the lens epithelium in the rat fetus. The pyknotic cells in the inner plate of the optic cup and the lens epithelium were positive for cleaved caspase-3 and TUNEL staining. Cleavage of caspase-3 is known to be involved in cell apoptosis, and is recognized as an apoptosis marker ${ }^{17}$. These results indicate that the pyk-

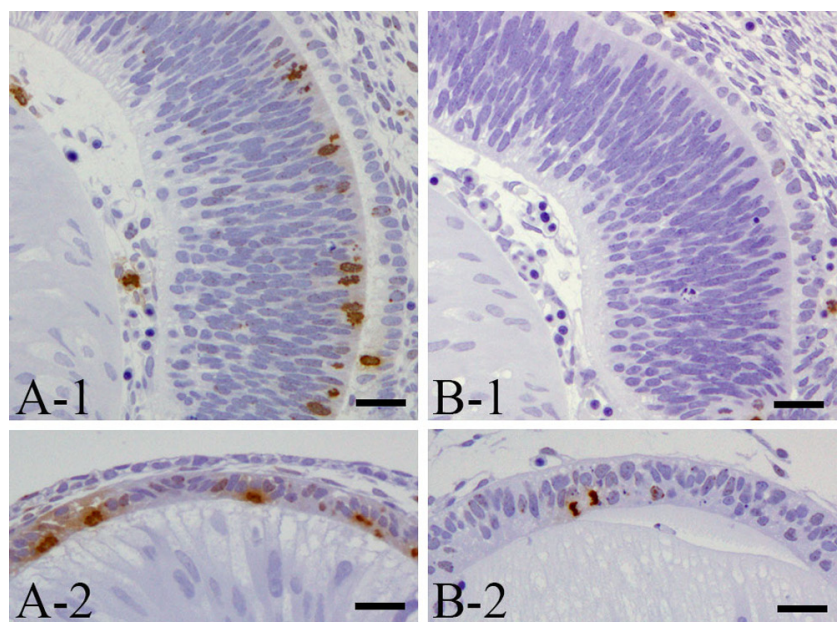

Fig. 11. Inhibition of cell proliferation in the inner plate of the optic cup induced by MTX on GD 13.5. A. Control group. B. MTX group. Immunohistochemistry for phospho-histone $\mathrm{H} 3$. $\mathrm{Bar}=$ $30 \mu \mathrm{m}$.
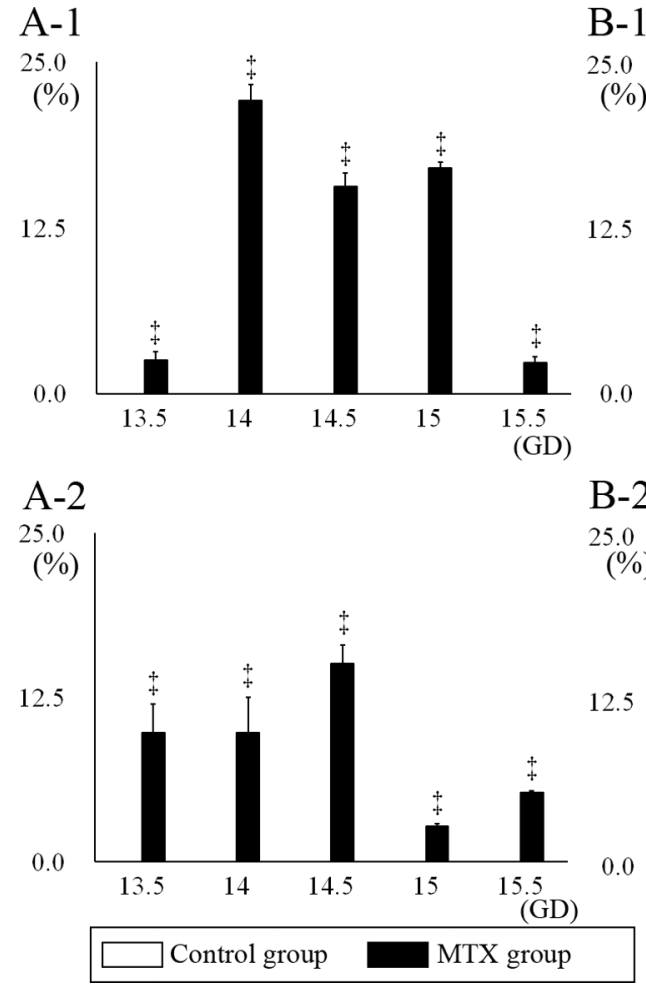

B-1

25.0
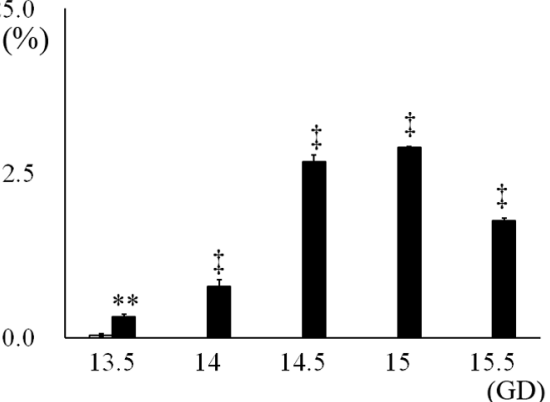

B-2

(GD)

C-1

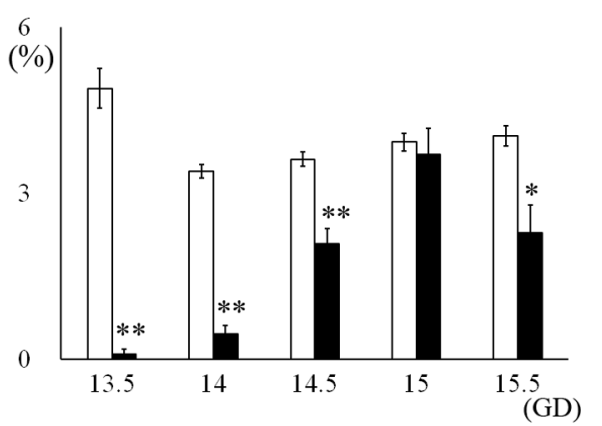

C-2

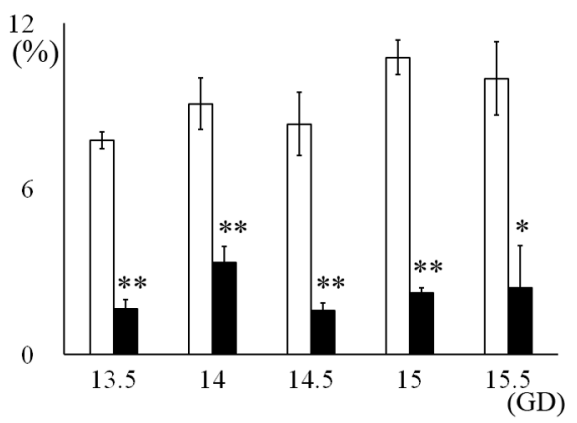

Fig. 12. Time course changes in the cleaved caspase 3-positive rate (A), the TUNEL-positive rate (B), and the phospho-histone H3-positive rate (C) in the inner plate of the optic cup (1) and lens epithelium (2). Values are expressed as means \pm SE. **Significantly different from the control group at $p<0.01$ (Student's $t$-test). ${ }^{\dagger}$ Significantly different from the control group at $p<0.01$ (Welch’s $t$-test). *Significantly different from the control group at $p<0.05$ (Mann-Whitney $U$ test). 
notic changes induced by MTX in the present study were caused by apoptosis. In the present study, marked increases in the cleaved caspase-3-positive rate of the inner plate of the optic cup and the lens epithelium were observed earlier than those in their TUNEL-positive rate. This result may reflect that the cleavage of caspase-3 precedes DNA fragmentation in the process of apoptosis of the component cells in the inner plate of the optic cup and the lens epithelium induced by MTX. On the other hand, in the MTX group of the present study, whereas the phospho-histone H3-positive rate in the inner plate of the optic cup showed the recovery suggesting the compensatory changes for preceding apoptosis and cell proliferation inhibition, the recovery was not observed in the lens epithelium. This result suggests that there is a difference between the sensitivity of the inner plate of optic cup for MTX and that of the lens epithelium.

Marked thinning of the inner plate of the ocular cup was observed in the MTX group of the present study. It is considered that this histopathological change is associated with the apoptotic change and cell proliferation inhibition in the inner plate of the optic cup induced by MTX. Similar histopathological changes are observed in ocular disorder induced by busulfan, a DNA damaging factor similar to MTX, in rat fetuses ${ }^{12}$. Busulfan treatment on GD 12 to 14 in rats induced apoptosis and inhibited cell proliferation in the neural retina on GD 14.5, 15, and 16, resulting in the retinal hypoplasia with a reduction in the thickness of the outer nuclear layer and outer plexiform layer on GD $21^{12}$.

In the present study, incomplete development of the ganglion cell layer in the inner plate of the optic cup was observed in the MTX group on GD 15 and 15.5. In rats, the ganglion cells began to develop around GD 14 or $15^{13}$. It is assumed that the incomplete development of the ganglion cell layer in GD 15 and 15.5 observed in the present study was caused by apoptotic changes and cell proliferation inhibition in the inner plate of optic cup induced by MTX on GD 14 to 15 . On GD 14 in rats, the ganglion cells project axons through glial channels on the retinal surface ${ }^{18}$. Then, the axon of the ganglion cell outgrows into the optic stalk to form the optic nerve fibers ${ }^{18,19}$. These results suggest that hypoplasia of optic nerve fibers on GD 15 and 15.5 in the MTX group in the present study arose from incomplete development of the ganglion cell layer.

In rat fetuses, the posterior lens vesicle cells elongate to form the primary lens fiber cells during GD 13, and the primary lens fiber cells contact the lens epithelium by GD $14^{20}$. The lens epithelial cells proliferate in the germinative zone of the lens epithelium ${ }^{21,22}$. The lens epithelial cells newly produced in the germinative zone move into the equatorial region, where they differentiate into lens fibers ${ }^{21}{ }^{22}$. New lens fiber cells move from the equatorial region to the outer cortex of the lens and form layers around the primary lens fibers ${ }^{21}$. In the present study, the disturbance of the arrangement of lens fiber cells observed in rat fetuses of the MTX group may arise from apoptosis and cell proliferation inhibition of lens epithelial cells. Alternatively, MTX may induce incomplete development of primary lens fibers or migration or differentiation disorder of lens fiber cells, and this may have caused the disarrangement of lens fiber cells on GD 15 and 15.5 in the present study. Eleven grays of soft Xradiation, a DNA damaging factor similar to MTX, induced abnormal migration of lens epithelial cells ${ }^{23}$. Busulfan treatment on GD 12 to 14 in rats inhibited cell proliferation in the equatorial zone of the lens and induced apoptosis in the lens epithelial cells on GD 14.5, 15, and 16, and it reduced the cell density in the nuclear bow and the equatorial zone on GD 16, resulting in swollen, fragmentary, and vacuolar lens fibers in the anterior region and poor development of the posterior region on GD $21^{12}$.

MTX treatment causes depletion of folate stores ${ }^{24,25}$. Folates are essential for one-carbon unit transfer reactions which are important for (1) synthesis of purine and thymidine precursors of nucleic acid 26,27 ; (2) metabolism of amino acids, e.g., conversion of homocysteine to methionine or cysteine ${ }^{3,25}$; and (3) synthesis of s-adenosylmethionine, which is the major methyl group donor for the majority of methylation reactions ${ }^{26,27}$. In mice, a maternal folate deficiency caused anophthalmia, microphthalmia, and dysplasia of the optic cup, ciliary body and iris, vitreous body, lens, and cornea ${ }^{28}$. In rats, folate deficiency on GD 7 to 9 induced aplasia or hypoplasia of the optic nerve on GD 16 and $17^{19}$. A previous study suggested that aplasia or hypoplasia of the optic nerve was associated with dysgenesis of the outgrowth of axons from the ganglion cells of the retina into the optic stalk induced by folate deficiency ${ }^{19}$. Other studies showed that folate deficiency and MTX exposure induced hyperhomocysteinemia ${ }^{29}, 30$. Interestingly, an earlier investigation demonstrated that a high level of exogenous homocysteine caused developmental disorders of the eyeball in chickens such as microphthalmia and lens dislocation ${ }^{31}$.

In the present study, eyeballs in the MTX group were small compared with those in the control group. Although the actual cause and the pathologic mechanism of this histopathological finding remain unclear, it may be associated with systematic growth disturbance induced by MTX. A previous study showed that prenatal MTX exposure induced fetal hypotrophy in rats ${ }^{32}$.

In conclusion, MTX administration at $90 \mathrm{mg} / \mathrm{kg}$ on GD 13 induced severe apoptotic changes and inhibited markedly cell proliferation in the inner plate of the optic cup and the lens epithelium. Thinning of the inner plate of the optic cup, disturbance of the arrangement of the lens fiber cells, an undeveloped ganglion cell layer, narrowing of the hyaloid cavity of the optic cup, and hypoplasia of the optic nerve were observed in the MTX-treated group. These results suggested that the optic tissue on GD 13 in rats was sensitive to MTX and that development of the eye in this period required a suitable amount of folic acid. The results of the present study thus draw attention to the overall fetal toxicity induced by MTX and the significant role of folic acid in eye development in the middle pregnancy period of rats. 


\section{References}

1. Rajamani R, Muthuvel A, Senthilvelan M, and Sheeladevi $R$. Oxidative stress induced by methotrexate alone and in the presence of methanol in discrete regions of the rodent brain, retina and optic nerve. Toxicol Lett. 165: 265-273. 2006. [Medline] [CrossRef]

2. Wessels JA, Huizinga TW, and Guchelaar HJ. Recent insights in the pharmacological actions of methotrexate in the treatment of rheumatoid arthritis. Rheumatology (Oxford). 47: 249-255. 2008. [Medline] [CrossRef]

3. Kobayashi K, Terada C, and Tsukamoto I. Methotrexateinduced apoptosis in hepatocytes after partial hepatectomy. Eur J Pharmacol. 438: 19-24. 2002. [Medline] [CrossRef]

4. Spurlock CF 3rd, Tossberg JT, Fuchs HA, Olsen NJ, and Aune TM. Methotrexate increases expression of cell cycle checkpoint genes via JNK activation. Arthritis Rheum. 64: 1780-1789. 2012. [Medline] [CrossRef]

5. Müller M, Strand S, Hug H, Heinemann EM, Walczak H, Hofmann WJ, Stremmel W, Krammer PH, and Galle PR. Drug-induced apoptosis in hepatoma cells is mediated by the CD95 (APO-1/Fas) receptor/ligand system and involves activation of wild-type p53. J Clin Invest. 99: 403-413. 1997. [Medline] [CrossRef]

6. Herman S, Zurgil N, and Deutsch M. Low dose methotrexate induces apoptosis with reactive oxygen species involvement in T lymphocytic cell lines to a greater extent than in monocytic lines. Inflamm Res. 54: 273-280. 2005. [Medline] [CrossRef]

7. Genestier L, Paillot R, Quemeneur L, Izeradjene K, and Revillard JP. Mechanisms of action of methotrexate. Immunopharmacology. 47: 247-257. 2000. [Medline] [CrossRef]

8. Kozma C, and Ramasethu J. Methotrexate and misoprostol teratogenicity: further expansion of the clinical manifestations. Am J Med Genet A. 155A: 1723-1728. 2011. [Medline] [CrossRef]

9. Hyoun SC, Običan SG, and Scialli AR. Teratogen update: methotrexate. Birth Defects Res A Clin Mol Teratol. 94: 187-207. 2012. [Medline] [CrossRef]

10. Adam MP, Manning MA, Beck AE, Kwan A, Enns GM, Clericuzio C, and Hoyme HE. Methotrexate/misoprostol embryopathy: report of four cases resulting from failed medical abortion. Am J Med Genet A. 123A: 72-78. 2003. [Medline] [CrossRef]

11. Jordan RL, Wilson JG, and Schumacher HJ. Embryotoxicity of the folate antagonist methotrexate in rats and rabbits. Teratology. 15: 73-79. 1977. [Medline] [CrossRef]

12. Furukawa S, Usuda K, Abe M, and Ogawa I. Microencephaly and microphthalmia in rat fetuses by busulfan. Histol Histopathol. 22: 389-397. 2007. [Medline]

13. Kuwabara T, and Weidman TA. Development of the prenatal rat retina. Invest Ophthalmol. 13: 725-739. 1974. [Medline]

14. Hendzel MJ, Wei Y, Mancini MA, Van Hooser A, Ranalli T, Brinkley BR, Bazett-Jones DP, and Allis CD. Mitosis-specific phosphorylation of histone $\mathrm{H} 3$ initiates primarily within pericentromeric heterochromatin during G2 and spreads in an ordered fashion coincident with mitotic chromosome condensation. Chromosoma. 106: 348-360. 1997. [Medline] [CrossRef]
15. Duregon E, Molinaro L, Volante M, Ventura L, Righi L, Bolla S, Terzolo M, Sapino A, and Papotti MG. Comparative diagnostic and prognostic performances of the hematoxylin-eosin and phospho-histone $\mathrm{H} 3$ mitotic count and Ki-67 index in adrenocortical carcinoma. Mod Pathol. 27: 1246-1254. 2014. [Medline] [CrossRef]

16. Veras E, Malpica A, Deavers MT, and Silva EG. Mitosisspecific marker phospho-histone $\mathrm{H} 3$ in the assessment of mitotic index in uterine smooth muscle tumors: a pilot study. Int J Gynecol Pathol. 28: 316-321. 2009. [Medline] [CrossRef]

17. Gown AM, and Willingham MC. Improved detection of apoptotic cells in archival paraffin sections: immunohistochemistry using antibodies to cleaved caspase 3. J Histochem Cytochem. 50: 449-454. 2002. [Medline] [CrossRef]

18. Sefton AJ, Horsburgh GM, and Lam K. The development of the optic nerve in rodents. Aust N Z J Ophthalmol. 13: 135-145. 1985. [Medline] [CrossRef]

19. Armstrong RC, and Monie IW. Congenital eye defects on rats following maternal folic-acid deficiency during pregnancy. J Embryol Exp Morphol. 16: 531-542. 1966. [Medline]

20. McAvoy JW, Chamberlain CG, de Iongh RU, Hales AM, and Lovicu FJ. Lens development. Eye (Lond). 13(Pt 3b): 425-437. 1999. [Medline] [CrossRef]

21. Graw J. Cataract mutations and lens development. Prog Retin Eye Res. 18: 235-267. 1999. [Medline] [CrossRef]

22. Yamamoto N, Majima K, and Marunouchi T. A study of the proliferating activity in lens epithelium and the identification of tissue-type stem cells. Med Mol Morphol. 41: 83-91. 2008. [Medline] [CrossRef]

23. Wolf N, Pendergrass W, Singh N, Swisshelm K, and Schwartz J. Radiation cataracts: mechanisms involved in their long delayed occurrence but then rapid progression. Mol Vis. 14: 274-285. 2008. [Medline]

24. Barford PA, Blair JA, and Malghani MA. The effect of methotrexate on folate metabolism in the rat. Br J Cancer. 41: 816-820. 1980. [Medline] [CrossRef]

25. Schalinske KL, and Steele RD. Methotrexate alters carbon flow through the hepatic folate-dependent one-carbon pool in rats. Carcinogenesis. 17: 1695-1700. 1996. [Medline] [CrossRef]

26. Araújo JR, Martel F, Borges N, Araújo JM, and Keating E. Folates and aging: Role in mild cognitive impairment, dementia and depression. Ageing Res Rev. 22: 9-19. 2015. [Medline] [CrossRef]

27. Reynolds E. Vitamin B12, folic acid, and the nervous system. Lancet Neurol. 5: 949-960. 2006. [Medline] [CrossRef]

28. Maestro-de-las-Casas C, Pérez-Miguelsanz J, López-Gordillo Y, Maldonado E, Partearroyo T, Varela-Moreiras G, and Martínez-Álvarez C. Maternal folic acid-deficient diet causes congenital malformations in the mouse eye. Birth Defects Res A Clin Mol Teratol. 97: 587-596. 2013. [Medline] [CrossRef]

29. Ansari R, Mahta A, Mallack E, and Luo JJ. Hyperhomocysteinemia and neurologic disorders: a review. J Clin Neurol. 10: 281-288. 2014. [Medline] [CrossRef]

30. Celtikci B, Lawrance AK, Wu Q, and Rozen R. Methotrexate-induced apoptosis is enhanced by altered expression of 
methylenetetrahydrofolate reductase. Anticancer Drugs. 20: 787-793. 2009. [Medline] [CrossRef]

31. Maestro de las Casas C, Epeldegui M, Tudela C, VarelaMoreiras G, and Pérez-Miguelsanz J. High exogenous homocysteine modifies eye development in early chick em- bryos. Birth Defects Res A Clin Mol Teratol. 67: 35-40. 2003. [Medline] [CrossRef]

32. Tshibangu K, Leroy F, and Doumont-Meyvis M. Effects of amethopterin (methotrexate) on the evolution of pregnancy in rats. Toxicology. 4: 65-73. 1975. [Medline] [CrossRef] 